\title{
LA FOTOGRAFIA Y EL RELATO. HERRAMIENTAS ETNOGRÁFICAS UTILIZADAS CON JÓVENES MAYAS DE YUCATÁN PARA DOCUMENTAR COSTUMBRES DE SU PUEBLO
}

NATALIA HERnÁNDEZ TANGARIFE Instituto Nacional de Antropología e Historia - Centro INAH Yucatán nataliahdz@gmail.com

RESUMEN: Este artículo expone la experiencia del trabajo de campo en un pueblo maya de Yucatán (México), donde se vinculó con un grupo de jóvenes para documentar una costumbre relacionada con el culto a los santos. Esto, en un intento de incursionar en la investigación como un medio de reflexión, de obtener una suma de perspectivas que permitieran la reflexividad de la práctica social a documentar desde el carácter dinámico que la caracteriza. Se exploran los conceptos de identidad y pertenencia vinculados a las costumbres y sus transformaciones, desde la exploración de una propuesta teórico-metodológica: la investigación como un derecho humano fundamental, y el relato y la fotografía como medio de apropiación de la investigación por los sujetos. A través de ello, se busca generar una visualidad electrónica para que los grupos sociales minoritarios ingresen con sus propios significados en la circulación de significados mercantilizados.

PALABRAS CLAVE: etnografía colaborativa; comunidades indígenas; maya-hablantes; Yucatán; fiestas patronales; visualidad electrónica. 
ABSTRACT: This article describes field work conducted in a Maya village in Yucatan (Mexico) to document a custom among a group of young people who worship the saints. The aim is for the research to also serve as a means for reflecting on the various perspectives on a dynamic social practice. The concepts of identity and belonging are explored in relation to customs and their transformations. The theoretical and methodological basis of the study is research as a fundamental human right, and the use of stories and photographs as the means by which the subjects can appropriate the research for themselves. The aim is to generate electronic visibility so that minoritized social groups can add their own meanings to the market of commercialized meanings.

KEYWORDS: collaborative ethnography; indigenous communities; Mayan speakers; Yucatan; saints' feasts; electronic visibility 


\section{Introducción}

Los gremios patronales en honor a la Virgen de Fátima de Popolá se celebran en el mes de mayo del día 1 al día 13. El gremio patronal es una celebración anual que los habitantes de los pueblos realizan en adoración a su santo patrono, aquella figura instaurada en cada poblado desde la colonia española en América, y que resulta ser la habitante más antigua que ha visto pasar familias y generaciones completas del pueblo. Los gremios varían de pueblo en pueblo, pero en el caso de Popolá consisten en trece días ${ }^{1}$ continuos de agradecimientos, ofrentas y fiestas, en los cuales existe un devoto por cada día. El devoto paga la misa ese día, se lleva en procesión a la Virgen a su casa, donde le ofrece flores, velas de cera de abejas manufacturadas in situ, una novena, comida, cohetes, música y la fiesta, que continúa hasta largas horas de la noche, aún después de que la Virgen regrese a la iglesia al finalizar la tarde.

Estos gremios que los habitantes ofrecen al santo patrono en agradecimiento a su protección y permanencia en el pueblo forman parte de su identidad desde las prácticas formalizadas que a través de generaciones se realizan y que conllevan una serie de relaciones sociales en el interior y en el exterior de su población. El gremio, como un proceso social, refleja un sentimiento, una relación de intercambio de favores y agradecimiento, es un esfuerzo social y económico para una persona o familia del que se espera garantías; es una práctica construida histórica y socialmente en cada poblado, que finalmente conllevó que se convirtiera en una costumbre (Hobsbawm, 2002).

Es así como el santo patrono representa una dualidad como objeto y como símbolo con su mayor expresión en los gremios patronales, y esta etnografía se desarrolla desde la documentación de esta costumbre, pero de una manera colaborativa con jóvenes del pueblo de Popolá. El acercamiento con Popolá parte de una relación de confianza previamente establecida debido a la restauración de otros santos patronos: el Santo Cristo del Amor y la Virgen de la Merced, esculturas policromadas del siglo xviII. Su restauración fue financiada de manera colaborativa entre la

1 Popolá cuenta con dos santos patronos más a quienes realizan, asimismo, gremios patronales: el Santo Cristo del Amor, del 1 al 24 de enero, y la Virgen de Fátima, del 1 al 22 de septiembre. 
comunidad católica de Popolá, la Secretaría de Cultura y Artes de Yucatán, el Instituto Nacional de Antropología e Historia - INAH Yucatán-y la Escuela Nacional de Conservación, Restauración y Museografía de la Ciudad de México -ENCRyM INAH—, en los años 2015 y 2016. Los jóvenes que se convocaron en ocasión de esta etnografía en ese entonces eran maestros de catequesis y se realizaron varias actividades con ellos como mediadores entre la comunidad y los restauradores.

Se conformó un grupo de diez jóvenes, todos exmaestros de catequesis, con el objetivo de reflexionar sobre lo que les es propio y llegar a construir en conjunto descripciones y significados de su contexto cultural, con el propósito de ingresar en una circulación de significados (Grimson, 2009) para fortalecer al pueblo maya-hablante de Yucatán desde su juventud. Esto debido a que las minorías étnicas en muchas ocasiones han adoptado y renunciado a lo propio, a causa de la circulación intensa de significados culturales en una sola dirección. No obstante ello, es notorio que los pueblos maya-hablantes de Yucatán han resistido a través de mantener su cosmovisión: la lengua maya, la milpa, los ciclos de vida, los patrones de residencia y de herencia, la forma de vestir, el mundo ritual y la religiosidad colectiva (Pérez Ruiz, 2015), y esta investigación busca sumar a esta intensión de resistencia.

En este trabajo, la investigación como proceso se definió como un derecho fundamental que proporciona a los jóvenes las herramientas que Arjun Appaduraid menciona en su trabajo con jóvenes en Mumbai: para descubrir a través de la observación empírica del mundo y la actividad humana un elemento para adquirir conocimiento y ejercer los derechos como ciudadanos democráticos (Appadurai, 2015, p. 373). Por tanto, esta etnografía colaborativa parte de la construcción del objeto de estudio con los jóvenes, y la documentación de este, con herramientas como la fotografía y el relato como medio para obtener un registro gráfico y documental de las costumbres de los pueblos maya-hablantes de Yucatán desde sus propias experiencias.

La cámara de fotografía análoga como mediadora entre el sujeto y la práctica se descubre como elemento que da forma a la expresividad y espontaneidad del momento. Y su resultado, la foto, como elemento 
material que también cumple una dualidad — la de objeto y la de símbolo al retratar un espacio-tiempo-, será relatado por la visión de los jóvenes. La visualidad que otorga la fotografía entra a formar parte de la circulación de significados que pretendemos, y la visualidad electrónica (Martín-Barbero y Corona Berkin, 2017) brindará el espacio propicio para esto. Por esto, la colaboración con jóvenes del pueblo resultó fundamental para estructurar esta investigación.

\section{Los gremios patronales y lo socialmente compartido}

Popolá es un pueblo con aproximadamente 5.000 habitantes maya-hablantes casi en su totalidad y se localiza a tan solo cinco kilómetros kilómetros de su cabecera municipal, Valladolid, que presenta 50.000 habitantes. Es la segunda población más grande de este municipio y es uno de los tantos poblados de esta región oriental del estado de Yucatán que se caracteriza por la abundancia de poblaciones maya-hablantes - de pequeñas a medianas de entre 500 y 5000 habitantes- que confluyen en Valladolid, el centro urbano más importante de la región. Se encuentra, además, inmersa en medio de un complejo turístico caracterizado por las costas del mar caribe, a $60 \mathrm{~km}$ al oriente de la conocida Riviera Maya, restos arqueológicos tales como Tulum en la Riviera, o Chichen Itzá y Ek Balam, a $20 \mathrm{~km}$ al occidente y norte, respectivamente, todos con visitas de más de dos millones de turistas al año.

Los maya-hablantes han logrado mantener sus herencias culturales fuera de la política homogeneizadora que el Estado impuso después de la revolución, a principios del siglo xx. La lengua y su cultura permanecieron en la vida comunitaria, «esta cultura conserva su vigencia, se reproduce de muy diversas maneras y mantiene su diferencia con respecto a la sociedad que la envuelve y constriñe» (Bracamonte y Sosa y Lizama Quijano, 2003: 88). Los mayas de Yucatán corresponden a una de las comunidades indígenas más extensas que mantiene su lengua natal, representando el «31,7\% del total de los habitantes de la entidad mayores de cinco años que la hablan, que corresponden a 1.472 .683 personas» (Bracamonte y Sosa y Lizama Quijano, 2003: 90). 


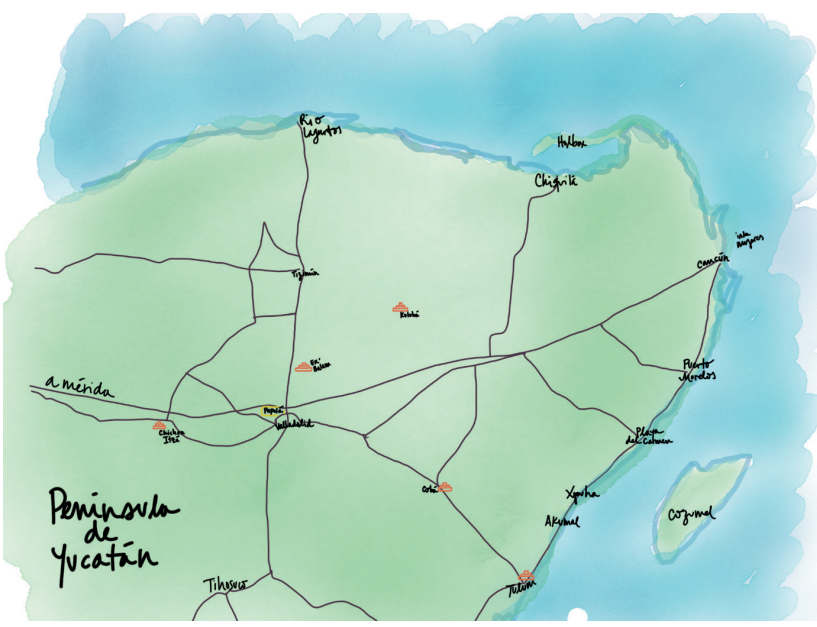

Mapa de la Península de Yucatán y ubicación del pueblo de Popolá.

La distribución geográfica de las actuales comunidades mayas de Yucatán es el resultado de procesos históricos, primero por las grandes ciudades mayas prehispánicas, posteriormente por la conquista y colonización de los españoles y más tarde durante el auge del henequén (fibra de agave). En época de la conquista, los misioneros franciscanos establecieron las cabeceras de parroquias en los centros indígenas más importantes donde residían los señores mayas de la zona y se encontraba la población en general. Construyeron iglesias y conventos en el mismo lugar de ubicación y con los mismos materiales que las construcciones mayas prehispánicas (Farriss, 2012: 204); con los españoles, la religión católica, creencias, tradiciones y la imaginería se instauran. Debido a ello, en todo el territorio yucateco se encuentran miles de poblados con templos católicos monumentales cada uno con un santo patrono, lo que resulta en más de 1.000 iglesias en los 106 municipios del estado de Yucatán e incalculables santos en cada uno de ellos.

El sincretismo religioso derivado de este engranaje cultural perdura hasta las comunidades maya-hablantes actuales. Ritos, ceremonias y prácticas en general en torno al catolicismo, la vida en común, los medios de producción, la materia prima y la cosmovisión se continúan realizando en los núcleos familiares y comunitarios de los pueblos de $\mathrm{Yu}$ - 
catán (Bracamonte y Sosa, 1994). Popolá y sus habitantes no escapan de este sincretismo y de manera latente se percibe en los actos en torno a la Iglesia, como la catequesis de los niños, por ejemplo, en ceremonias en la milpa para la lluvia y protección de la cosecha, o en ritos de paso que se efectúan en los núcleos familiares. Esta es la religión maya, como la denomina Nancy Farriss, «actividad social orientada a mantener el cosmos en funcionamiento $y$, por lo tanto, a garantizar la supervivencia de su componente humano» (Farriss, 2012: 377).

En este estudio de caso, el gremio patronal con su sincretismo religioso acumulado y transformado en el tiempo hace referencia a la religiosidad popular y común que los pobladores de Popolá han conformado como parte sustancial de su identidad y cosmovisión: «La fiesta se considera la mejor ocasión para establecer el diálogo del hombre necesitado con lo sobrenatural, expresado fundamentalmente a través de promesas y exvotos» (Rodríguez Becerra, 2012:4). Y la poca intromisión de la Iglesia al limitar su participación a oficializar la misa en los gremios patronales de los pueblos maya-hablantes lo reitera. Aunque la religiosidad popular de los maya-hablantes es definida por la doctrina y su visión de la Iglesia como autoridad no tiene duda, su religiosidad común se refiere al sincretismo de los mensajes que han sido adaptados y reelaborados por su propia cultura, y a una vivencia y participación comunal e individual que solo requiere a los párrocos para legitimar ciertos actos (Rodríguez Becerra, 2012: 4, 6).

Esta expresión colectiva que se vislumbra en los gremios patronales se inserta en discusiones sobre la identidad de los grupos minoritarios -como las comunidades indígenas-, denominándolos bajo el concepto de identidades étnicas. Cabe recordar que el concepto de minoría y de etnicidad parte de una construcción social que busca la diferenciación entre culturas y es «resultado histórico del proceso de denominación en el marco de la construcción del Estado» (Pujadas, 2011: 2). El moderno Estado nación conformó fronteras que delimitan los grupos humanos y con estas, la concepción de referentes identitarios para delimitarlas y personificar la nación. El concepto nación se ha construido bajo la idea de raza, referida a algo innato — comunidad de sangre y entidad biológi- 
ca- y como algo cultural, algo adquirido - lenguaje, costumbres, paisaje- (Todorov, 2013: 434). Usualmente encontramos dentro de una nación múltiples razas y culturas y su interacción se rige bajo los referentes de identidad que ha construido cada una. Sin embargo, las concepciones universalistas de las que surgen estos esquemas han determinado la supuesta superioridad de unas culturas sobre otras.

Es así como la diferenciación cultural parte de la interacción entre grupos étnicos (entendido como algo innato a la condición social de los hombres) y el contraste entre unos y otros determina su sentimiento de pertenencia y de resignificación de los referentes de identidad para construirlos o reconstruirlos (Pujadas, 2011: 11). La formación del nosotros somos hace parte de ese contraste entre unos y otros, es constante en el tiempo y «cambia junto con los contenidos culturales y los contextos sociales en los que se manifiesta, ya que no hay identidades inmutables sino procesos sociales de identificación» (Bartolomé, 2006:37).

En este orden de ideas, los grupos sociales vistos como grupos étnicos están enmarcados en un contexto racial (innato) y cultural (adquirido), y este último, «indispensable para el florecimiento de todo individuo [...] es en esto en lo que se es humano» (Todorov, 2013: 435). Sin embargo, esta adquisición puede ser impuesta por un referente estatal, como mencionábamos, parte de la construcción de las naciones, o creada y mantenida por los grupos sociales. Independientemente de ello, es un componente poroso y la circulación de rasgos culturales, materiales y simbólicos es inevitable entre los grupos sociales (Bartolomé, 2006: 36). Para E. Hobsbawm (2002) la tradición es una invención del Estado nación con el propósito de estructurar unas prácticas y la vida social del colectivo que en él se enmarca.

El elemento de la invención es particularmente claro aquí desde el momento en que la historia que se convirió en parte del fundamento del conocimiento y la ideología de una nación, estado o movimiento no es lo que realmente se ha conservado en la memoria popular, sino lo que se ha seleccionado, escrito, dibujado, popularizado e institucionalizado por aquellos cuya función es hacer precisamente eso (Hobsbawm, 2002: 20). 
Distingue entre la tradición y la costumbre, siendo la primera algo estático, fijo y formal, y otorgando a esta última la característica de motor y engranaje susceptible a procesos de cambio e innovación (Hobsbawm, 2002: 8). En ocasiones se han tomado costumbres para formalizarlas o institucionalizarlas — patrimonializarlas-y darles el carácter de tradición estática de un grupo. Hecho evidente en diversas costumbres que han sido sujetas de esta objetivación en países como Bolivia o Ecuador en los que la exaltación de los pueblos originarios se ha vuelto esencial en la construcción de la nación, tal como lo expresa Eduardo Kingman (2011) en su estudio, y menciona:

[...] al patrimonializarla podría darse paso a su conversión en un recurso público de libre disposición — por encima de las necesidades de la propia comunidad-o en un recurso turístico y mediático. Y algo parecido sucede con las culturas: una vez patrimonializadas y convertidas en espectáculo, son separadas de la vida activa de la gente (Kingman Garcés, 2011: 232).

Por ello, dado el carácter histórico y social de nuestro contexto de estudio, se diferencia y caracteriza a los gremios patronales como costumbres, que aunque fueron instaurados a través de una figura -imagen de un santo-como protector de una comunidad con el fin de institucionalizar una nueva religión, las comunidades la dotaron de un carácter propio al margen de esta instauración vertical de poder. Los gremios patronales se caracterizan por reforzar los lazos sociales requeridos para su organización y ejecución, por unos símbolos y prácticas constituidos de manera autónoma con sus propios recursos y en relación con su contexto, y los cuales han variado e innovado conforme a los cambios sociales y materiales a través del tiempo.

Los gremios patronales en sus diferentes elementos compositivos, como parte de una herencia cultural o costumbre - como bien lo describíamos anteriormente - y como elemento de identidad de una población, han sido descritos en múltiples etnografías. Esta investigación se enfocó en comprender el sentido social, material y simbólico que representan los gremios patronales de Popolá desde los conceptos que algunos de los jóvenes de la población han definido como propios de esta celebración. 
Se partió de la propuesta de Gilberto Giménez (2004) sobre los procesos y acciones sociales que construyen y mantienen una identidad colectiva. Lo socialmente compartido (Giménez, 2004: 86), tal como la denomina, hace referencia a una red de relaciones e interacciones entre actores que se influyen y toman decisiones de manera conjunta, y a un «involucramiento individual que permite a individuos sentirse parte de una común unidad» (2004: 93). Por tal razón, «la permanencia de una identidad debe ser producida continuamente» (Giménez, 2004: 93), aspecto clave para comprender los elementos de los gremios patronales no como algo estático en el tiempo sino como una herencia cultural viva - una costumbre- en permanente transformación.

Los santos patronos cumplen esa función de lo socialmente compartido. En el nombre de los santos patronos se expresa la colectividad como parte de un proceso que año tras año se reafirma, se reapropia, se transforma. La congregación de los colectivos en espacios específicos permite que la identidad se sociabilice y se comparta, así como el manejo de los símbolos que esta celebración conlleva, pues «hace a un individuo ser plenamente reconocido como miembro de un específico grupo humano» (Bartolomé, 1997: 99).

Se comprueba de este modo que los sujetos son activos en su contemporaneidad, es decir, aunque se reproduzcan elementos materiales y simbólicos, es la interacción social la que da forma y significado a su expresión. Los gremios patronales son el elemento que permite la interacción social para reafirmar lo socialmente compartido, su riqueza se traduce en las redes sociales que se tejen en su nombre (Pitarch, 2012) sobre aquellos elementos materiales realizados para esta celebración y hasta el mismo santo, quien es el que lo permite. Lo demuestra la relación subjetiva entre comunidad y santo patrono que se establece, pues «el santo muestra que el bienestar siempre implica la producción de la subjetividad en el otro: los pobladores piden al santo que actúe, y este en consecuencia, actúa sobre ellos» (Magazine, 2012: 126); así el investigador puede llegar a impactar en su contexto de estudio.

Así las cosas, el enfoque se gira a las maneras de reconocer las expresiones culturales y memorias colectivas (en este caso, mayas contempo- 
ráneas) frente a otras, para «fortalecer las peculiaridades culturales e identitarias» (Pérez Ruiz, 2015: 462) y reflexionar sobre ellas, lograr posicionarlas frente al contexto mundial por sus actores sociales y contribuir en su preservación a través de la documentación. Perez Ruiz (2015) reconoce el conflicto existente entre las identidades colectivas e individuales de los jóvenes mayas a través de las maneras de «expresión individual, libertad e independencia» que estos reclaman como formas de participar en la modernidad y la conexión transnacional; y cómo estos procesos subjetivos de «interiorización, autoconciencia y reelaboración de la cultura» son los referentes de sus fronteras culturales a través de los cuales construyen sus «procesos de inclusión, exclusión y autorreconocimiento» (Pérez Ruiz, 2015: 134).

Este proceso de deslocalización (Pujadas, 2006) de los jóvenes es generado por el contexto cultural contemporáneo donde los medios masivos de comunicación y la mercantilización son los nuevos colonizadores de la sociedad, pues definen la producción cultural, su distribución y su consumo acrecentando una alienación cultural (ibid.). Por ello, la manera de asumir y percibir su sentido de pertenencia al grupo étnico - lo socialmente compartido- marcará su posicionamiento frente a la cultura local, su conservación o su abandono hasta su olvido en pro de la alienación global.

Lo dicho por el momento, y según el contexto social que atañe, nos enfrenta a una población que vive y siente una diferencia étnica y procesos de desigualdad y exclusión social. Cabe recordar que estos han sido construidos históricamente bajo los hechos sociales, políticos y económicos que han acontecido sobre este territorio de la península de Yucatán densamente poblado por comunidades indígenas sometidas a la colonización y el imperialismo. No obstante, existe un elemento más el cual añadir a la diferencia, la desigualdad y la deslocalización anteriormente mencionada, y que corresponde a la desconexión, «la capacidad o la oportunidad de moverse, mantener redes multiconectadas» (García Canclini, 2014: 129). Según Canclini, ahora la sociedad se concibe en la metáfora de la red: movilidad y conexiones (ibid.: 127), y el problema es llegar a ser «incluidos, llegar a conectarse, sin que se atropelle su diferencia ni se los condene a la desigualdad» (ibid.: 119). 
Redondeada así la noción, el objetivo no es documentar la diferencia cultural, sino aprovecharla para desde ella contribuir al autorreconocimiento para la conexión intercultural; diferencia cultural que las poblaciones jóvenes de contextos indígenas tienen inferiorizada o menospreciada frente a la influencia cultural de la otredad dominante. Es hallar puntos de cruce de perspectivas y de intersección evitando las absolutizaciones y los esencialismos culturales ( $i b i d$.) y permear en la porosidad de las fronteras culturales y contribuir a la circulación de significados (Grimson, 2009). Esto, a través de la metáfora de la red a la cual aludíamos anteriormente y que el filósofo Raimon Panikkar también referencia frente a un contexto más amplio como es la humanidad, al definirla como «la labor filosófica de intentar ser conscientes del propio mito, de cuestionarlo y de transformarlo, de encontrar equivalencias entre discursos culturales diferentes» (Panikkar, 2006), para contribuir al diálogo entre culturas, la interculturalidad, ahora contextualizada a un espacio de conexión virtual.

\section{La imagen como medio: propuesta para una etnografía colaborativa}

Lo anterior conduce al cuestionamiento de las maneras de cómo generar este tipo de reflexiones con los actores sociales a los se ha referido. La base conceptual se toma de Arjun Appadurai (2015), que habla de la investigación como derecho fundamental bajo la premisa de que «todos los seres humanos somos investigadores» (Appadurai, 2015: 355) y la investigación es un espacio para el descubrimiento a través de la observación empírica del mundo y la actividad humana. Comenta que es necesario adquirir conocimiento para ejercer nuestros derechos como ciudadanos democráticos, como herramienta de cambio social, y considera la documentación como un medio de intervención social para empoderar a los individuos y sus colectivos (ibid.: 373).

La propuesta de este autor hace referencia a la investigación de sus propios conocimientos y sus vidas, de sus contextos cotidianos, como la ciudad, el barrio, la calle o las familias, para tratarlos como objetos de 
estudio y como contextos susceptibles de cambio. Así, la capacidad de investigación se une a la capacidad de aspiración, requerida como presión para saber más (op. cit.). Con ello, la acción y el conocimiento se entrecruzan en un objetivo común que es la documentación como medio de apropiación de las investigaciones sociales.

Paulo Freire (1976) se refería a este tipo de acción en los años setenta frente a la problemática de la enseñanza, al confiar en la autorreflexión del espacio-tiempo de los individuos. El interrogarse sobre lo cotidiano permite profundizar en la toma de conciencia como sujetos y autores de la historia, que dirige a un proceso de construcción de conocimientos a través de la discusión colectiva de temáticas específicas (Freire, 1976: 26). Esta es la sociedad aprendiente que propone Hugo Assmann (2002), que nunca debe dejar de cuestionarse ni de investigar sobre su entorno cotidiano, una sociedad que «debe entrar en un estado de aprendizaje y transformarse en una inmensa red de ecologías cognitivas» (Assmann y Boff, 2002: 19) que ocupe los accesos al conocimiento y proponga nuevas maneras cognitivas de los sujetos y colectivos con el fin de alcanzar «metas vitalizadoras del tejido social» (ibid.: 27).

Derivado de lo anterior, la propuesta se dirige a una intervención social que toma como referencia el patrimonio inmaterial asociado al patrimonio histórico en el sentido de establecer un objetivo concreto, un campo de acción específico que delimite la intervención. En este caso, la intervención social se dirige a que el actor-sujeto investigado tenga voz en la etnografía a través de la documentación de los gremios patronales del pueblo (herencia inmaterial asociada a elementos materiales). $\mathrm{Al}$ hablar de documentación nos referimos a la construcción de marcos de referencia de un elemento específico, y para ella la imagen - a través de la fotografía - la tomamos como medio de documentación histórica de un tiempo y un espacio como medio visual que ayuda a narrar y materializar la práctica social.

La sociedad es productora de artefactos y la investigación arqueológica los ha caracterizado en un contexto histórico y tecnológico para reconocer a las sociedades que los han producido. Desde utilitarios, para la supervivencia y la producción de alimentos, a otros de carácter estético, como 
la pintura rupestre, pasando por esculturas y pinturas en papel, telas y muros, a la fotografía, entre muchos otros; la imagen ha sido uno de los medios de producción de significados que el ser humano ha creado para transmitir y para materializar su pensar y sentir. Al contemplar una fotografía observamos lo que ha sido, es así como la imagen se transforma en un signo, en metáfora, en imitación de la cosa (Eco, 1976: 109), que tiene como objetivo la transmisión e intercambio de información. Las fotografías son imágenes del mundo capturado en una instantánea, son ausencia y presencia transformando los sujetos en objetos, de tal forma que «es todo contingente [...] y solo puede significar» (Barthes, 1989: 46 y 76).

La fotografía es una novedad en la historia de la humanidad con tan solo 180 años de ser inventada marcó un hito en la historia y la historia del arte a causa de la reproducción de espacios y elementos de manera verídica y rápida, pues era posible retratar, sin discusión de autenticidad, hechos y espacios. Constituyó antropológicamente un testimonio del pasado, «del ordenamiento social del pasado y sobre todo de las formas de pensar y de ver las cosas en tiempo pretéritos» (Burke, 2001: 236). Esto es, una herramienta histórica, social y económica que nos permite conocer la historia de los espacios construidos, las prácticas en el espacio público y sus transformaciones físicas; son testimonios de culturas y de los modos de vida de la sociedad de la última mitad del siglo xIx, todo el siglo xx y del iniciado siglo xxi, ahora, a través de medios digitales.

Se inserta así otra cuestión con respecto a las imágenes como testimonios que corresponde a la decisión de los fotógrafos de los «aspectos del mundo que se van a retratar» (Burke, 2001: 27). Y las maneras en cómo los otros se retratan, no únicamente desde ese ojo externo que lo observa, retrata y describe, sino desde ellos mismos, y la posibilidad de que las fotografías entren en la red de movilidad y conexión que García Canclini indica. Si estamos en un contexto rural en donde ya existe el acceso a Internet por medio de los teléfonos móviles, es un hecho que la imagen entra en movimiento a través de la Red.

La visualidad electrónica ha entrado a formar parte constitutiva de la visualidad cultural, esa que es a la vez entorno tecnológico y nuevo imaginario. Pues lo que las nuevas visualidades provenientes de la televisión, 
el videojuego y el hipertexto ponen hoy en juego no es únicamente la hibridación de las lógicas globales del capital con las nuevas expresiones de un exotismo a admirar o a denunciar sino hondas transformaciones de la cultura cotidiana (Martín-Barbero y Corona Berkin, 2017: 47).

Jesús Martín-Barbero, especialista en medios de comunicación y cultura, se ha dedicado al impacto de los medios masivos de comunicación en las sociedades. Su última publicación, Ver con los otros (Martín-Barbero y Corona Berkin, 2017), en coautoría con la comunicóloga Sarah Corona Berkin, nos remite a la problemática que pretendemos abordar. Sus palabras conducen a la experimentación para la participación y expresión de la comunidad para «catalizar los nuevos modos de ver y oír, de leer y narrar» (Martín-Barbero y Corona Berkin, 2017: 30).

Otra técnica utilizada es la llamada photovoice (Wang, 1999), con la cual se identifica, representa e incentiva la voz de la comunidad. Esta técnica de investigación-acción participativa se ha utilizado en Asia en comunidades rurares chinas, para reconocer a través de las fotografías la realidad social retratada por sus propios actores. En estas experiencias resulta fundamental la interpretación de la imagen por quien ha tomado la foto, pues «the photovoice entails people's discussing the images that they have produced, and by doing so, they give meaning to, or interpret their images» (Wang, 1999: 186). El relato es complementario a la imagen y se ha de realizar desde la definición de cada fotografía, para posteriormente crear grupos de discusión donde se definan temáticas y problemáticas reconocidas desde la investigación. De esta manera, la voz de la comunidad se complementa entre la imagen y el relato.

Blanca Muratorio (2005) también retoma la cuestión de la autoría de las etnografías al analizar el trabajo de campo del antropólogo en contextos indígenas y los textos etnográficos resultantes. Para ella, el trabajo de campo significa introducirse en la práctica social del otro y ha de ser dialógico, es una reflexividad compartida que implica reconocerte en el otro (Muratorio, 2005: 131). Es decir, es un proceso de comprensión de las partes para la interpretación, reconocimiento y respeto de las culturas, y el verse reflejado en la realidad del otro - hecho filosófico que nos introduce en la comprensión entre culturas que Raimon Pannikar en su 
decálogo de cultura e interculturalidad menciona (Panikkar, 2006)-. Según Muratorio, este proceso tiene como fin «buscar una voz que cruce la barrera cultural y se dirija a audiencias académicas y nativas», así como encontrar un «balance entre lenguaje técnico y narrativo, mantener la oralidad de las fuentes» (Muratorio, 2005: 134).

La discusión se dirige a cómo conseguir desde los jóvenes una visión de su cosmovisión y de sus actitudes e interpretaciones de los gremios patronales. Gunther Dietz introduce la etnografía doblemente reflexiva entre el sujeto investigador y el actor-sujeto investigado (Dietz, 2012: 73) que remite a la relación dialógica. Esto, con el propósito de alcanzar una «circulación de saberes [que] [...] genera una creativa hibridación de conocimientos» (ibid.: 83), algo que la propia Muratorio clasifica como un proceso inevitable, ya que «al interpretar y transmitir esas memorias contribuimos a transformarlas» (Muratorio, 2005: 135).

Ya se comentó que la transformación de las prácticas sociales es inevitable, es un proceso continuo en el tiempo. Sin embargo, se aspira a incentivar cambios en el contexto social desde la creación de experiencias, establecer espacios de reflexión o también formando expertos (Pérez Ruiz y Argueta Villamar, 2011: 49).

Lo que nosotros llamamos la intervención social, y lo que tratamos de efectuar, es justamente crear experiencias con los jóvenes de Popolá. Por ello consideramos que la fotografía y el relato como medio de expresión y diálogo son idóneos para el contexto visual y virtual en que vivimos.

Nos hemos acostumbrado a observar fotos de los pueblos indígenas como parte de una mirada externa que pretende congelarlos un tiempo-espacio, como poseedores de los conocimientos de las culturas mesoamericanas y como símbolos de identidad de la nación mexicana. Las narrativas desde el sujeto - convertido en objeto retratado- son escasas y la antropología visual puede ayudar a convertir las visualidades en «la construcción tanto de las identidades como de las ciudadanías» (Martín-Barbero y Corona Berkin, 2017: 21).

No es únicamente ver las fotos que toman los demás, sino compartir su contexto social para conocer la realidad desde la cual se emplazan y así «comprender cómo se miran, cómo nos miran y cómo se entrelaza "su 
historia y la mía"» (ibid.: 75). La propuesta es generar en coautoría y en múltiples voces las investigaciones, lo cual se liga con el derecho a la investigación de Appadurai (2015) para incentivar a los jóvenes a retratar su cotidianidad de manera colectiva como punto de partida, se trata de realizar una construcción de conocimiento mutuo y conocimiento juntos.

En el contexto social, político y económico en que nos situamos, la hibridación cultural es más que notoria. Por ello, aunque exista un sincretismo en las prácticas rituales — sociales y simbólicas - heredado de generaciones atrás, también lo existe con la actualidad. La contextualización de los rituales, las prácticas o las narrativas, en este caso se refiere a:

[...] entender qué recursos culturales y simbólicos son usados en la producción de nuevas modernidades y qué lugar tienen las memorias históricas y las nuevas apropiaciones y re significaciones de los discursos de los otros en el presente y en la proyección hacia el futuro (Muratorio, 2005: 133).

Pues corresponde al punto de partida que ha de tomarse en el proceso dialógico, pues, asimismo, es el punto desde el cual ellos «dialogan con los discursos nacionales» (Rappaport y Ramos Pacho, 2005). Sea este un proceso que lleve a la alienación o, por el contrario, sea de resistencia, las formas culturales indígenas «son reimaginadas desde una perspectiva moderna, entremezcladas con apropiaciones de formas culturales de la sociedad mayor, produciendo una antifonía dinámica» (ibid.: 47). Es decir, como dijimos, no nos enfocamos en retratar la diferencia cultural, sino desde ella crear espacios de expresión y diálogo para la circulación de significados.

Finalmente, Martín-Barbero relaciona la fotografía con la conexión digital como método de transmisión de la información investigada, en este caso de la cotidianidad de Popolá y de los gremios patronales, y como medio de reflexión del grupo social dentro del marco de lo socialmente compartido, diciendo:

Las tecnologías y los lenguajes digitales deberían potencializar al máximo las formas de interactividad, no sólo como estrategia estrictamente pedagógica sino de educación ciudadana, esto es, de participación y ex- 
presión de la comunidad, y de innovación cultural que busca en la experimentación de los lenguajes audiovisuales catalizar los nuevos modos de ver y oír, de leer y narrar (Martín-Barbero y Corona Berkin, 2017:30).

\section{Construcción del objeto de estudio con los jóvenes de Popolá}

Al enfrentarnos al trabajo de campo, la conformación del grupo de investigación con jóvenes de Popolá se logró debido a que existía una relación construida en años anteriores al ejecutar los proyectos de conservación y restauración del Santo Cristo del Amor y la Virgen de la Merced. Este punto de partida facilitó el trabajo planeado y por venir. Se conformó un grupo de diez jóvenes (antiguos catequistas) con los que se inició la construcción del objeto de estudio y con quienes se realizaría la toma de fotografías en las fechas del gremio patronal de Popolá para retratar y relatar. Elena, Cristina, Magda, Lucy, Brenda y Deysy participaron constantemente en las sesiones de trabajo, todas mujeres entre 18 y 26 años, solteras, no estudiantes, que trabajan en sus casas y en el pueblo, en loncherías, tiendas y huertos de sus familiares, y nos encontrábamos para trabajar en las tardes después de los quehaceres cotidianos.

La construcción del objeto de estudio se conformó tras cuatro sesiones de trabajo. Desde una lluvia de ideas con respecto al tema central, los gremios y fiestas patronales, hasta la clasificación de los elementos identificados. El uso de la lengua maya fue constante en la interacción entre las jóvenes, por tal razón, establecer un diálogo continuo basado en sus discusiones internas de grupo fue complejo. Siempre traducían lo hablado entre ellas, o sencillamente la decisión tomada. No obstante, la lluvia de ideas trajo consigo los elementos que componen los gremios y las fiestas, reconocidos por las autoras debido a su participación continua desde que tienen uso de razón en estos eventos tan importantes para el pueblo de Popolá y su comunidad. Desde aquel primer momento, fue notorio que la investigación tomó la forma que las jóvenes decidieron, es decir, se construyó con base en los marcos de referencia cultural propios a estas, y no a los del investigador externo. 


\begin{tabular}{|c|c|c|}
\hline SANTOS & GREMIOS & FIESTAS \\
\hline Virgen de la Merced & Amor & Vaquería \\
\hline San Francisco de Asís & Favores & Ya'ax Che \\
\hline Cristo del Amor & Ramilletes & Músicos \\
\hline Virgen de Fátima & Promesas & Ternos \\
\hline Los milagros & Novenarios & Ruedo \\
\hline Las procesiones & Fe & Mestizos \\
\hline & Cantos & Alegría \\
\hline & Voladores & Corridas \\
\hline & Comidas regionales & Bailes \\
\hline & Devotos & Voladores \\
\hline & Misas & Charlotadas \\
\hline & Sacerdotes & Comunidad - la gente \\
\hline & Priostes & \\
\hline & Estandartes & \\
\hline & Velas & \\
\hline & Pan águila & \\
\hline
\end{tabular}

Tabla 1. Elementos que componen los santos, los gremios y las fiestas.

La diferenciación de los elementos correspondientes al gremio y a la fiesta fueron evidentes, algo que por mi parte no se comprendía hasta que ellas lo evidenciaron de manera sencilla. Los gremios y las fiestas son dos entidades diferentes en las celebraciones anuales en honor al santo patrono, cada uno presenta actos y eventos distintos aunque se realicen de manera paralela. En este sentido, tras identificar los elementos de cada uno, decidimos enfocar nuestros enfuerzos de documentación en únicamente los eventos y actos que acontecían alrededor de los gremios en honor a la Virgen de Fátima, próxima a celebrarse en el mes de mayo en Popolá.

Las jóvenes describieron de manera oral cada uno de los elementos que identificaron. Esta narración permitió reconstruir sistemáticamente los días y horas en que acontecía cada elemento, o las actividades de preparación previa que requerían los encargados de la celebración. Durante estos relatos, Elena, una de las integrantes del grupo de investigación, comentó que su papá, don Saturnino, sería el devoto del gremio mayor 
ese año, por lo cual podríamos tener acceso al núcleo de gestación de las actividades que implicaba realizar el gremio, y a su documentación fotográfica.

Tras la narración, se reclasificaron los elementos del gremio descritos por las jóvenes según su categoría: prácticas, objetos y el aspecto símbólico. Así, se obtendría un sistema de documentación mediante la fotografía de cada uno de los elementos identificados.

\begin{tabular}{|c|c|c|}
\hline PRÁCTICAS & OBJETOS & ASPECTO SIMBÓLICO \\
\hline Novenarios & Ramilletes & Amor \\
\hline Cantos & Voladores & Promesas \\
\hline Comida & Estandartes & Fe \\
\hline Misas & Velas & Milagros \\
\hline Procesiones & Pan de Águila & \\
\hline & $\begin{array}{c}\text { Virgen de Fátima } \\
\text { (material e inmaterial) }\end{array}$ & \\
\hline
\end{tabular}

Tabla 2. Clasificación de elementos que componen los gremios patronales de Popolá

Las prácticas y los objetos corresponden al aspecto tangible y observable de los gremios y los que se llegarían a documentar con las jóvenes, mientras que el aspecto simbólico como elemento intangible se debería identificar de otras maneras, como por medio de entrevistas de los conocimientos y sentimientos locales. En este sentido, los elementos tangibles, los objetos propiamente dichos, como ramilletes, voladores, estandartes, velas, pan águila y la comida, también, fueron los puntos focales de los que se partió para documentar con las jóvenes las prácticas que envuelven los gremios patronales de Popolá.

En el transcurso de los encuentros con las jóvenes no fue posible mantener una presencia constante de todas, pues en ocasiones tenían compromisos que evitaban su presencia y en otras asistían acompañadas de nuevos amigos que participaban en una sesión únicamente. Aunque la investigación continuaba y se actualizaba a los faltantes en los avances de la misma, sí existió un quiebre en la continuidad que nos afectó posteriormente al empezar los gremios. 
Tras la descripción de los elementos del gremio realizada por las jóvenes fue evidente que las actividades que acontecen en el mes de mayo en el pueblo de Popolá se toman por completo la cotidianidad del pueblo. Sin embargo, no se contaba con un itinerario específico sino disperso de estas actividades por elementos, por lo que una sesión más se dedicó a la descripción de lo que acontecía cada día. Este relato se realizó por escrito entre los participantes de la sesión y se detalló cada día del 1 al 13 de mayo en los eventos y actividades, con el propósito de programar la investigación en los días del evento.

Con los referentes simbólicos y materiales identificados de los gremios patronales de Popolá, aquellos que constituyen lo socialmente compartido (Giménez, 2004), la documentación propiamente dicha correspondió al siguiente paso de la investigación. Es así como la fotografía se toma como herramienta de documentación y como medio de apropiación de lo investigado. Lo que introduce el siguiente paso metodológico.

\section{Taller de retrato y relato}

Se consideró a la imagen como elemento ideal para lograr que la documentación fungiera como medio de apropiación de la investigación por parte de los jóvenes. Tal como se expresó en el apartado teórico, no dudamos de la capacidad de la imagen como recurso visual para transmitir y materializar la subjetividad. Así, se programó un taller experimental que se denominó «Retrato y relato», con el propósito de reflexionar sobre tres aspectos: a) la imagen como retrato de espacio-tiempo y una sociedad, b) la imagen como objeto, y c) la imagen como medio de expresión personal.

Se adquirieron cuatro cámaras de plástico réflex de formato mediano ${ }^{2}$ que permitirían una reflexión sobre los tres objetivos propuestos: el primero, sobre la selección de un momento a retratar; el segundo, sobre la fotografía en este caso análoga como elemento que permite el retrato y que permanece el tiempo en un soporte material como es el negativo y el papel fotográfico, y, por último, la fotografía como un medio de expresión visual de las jóvenes. Los relatos escritos de las fotografías refuerzan

2 Conocidas como Holga $120 \mathrm{~N}$ y sus rollos fotográficos de $120 \mathrm{~mm}$, que corresponden a cámaras de toma sencilla point and shut con únicamente dieciséis fotografías por rollo. 
la expresión escrita de las jóvenes, en ellos expresaron su visión, conocimiento y parecer de las prácticas y objetos que componen los gremios. También se realizaron fotografías digitales de los eventos a los que se asistió durante los gremios patronales, como refuerzo de la documentación análoga en caso de que la toma fotográfica análoga tuviera problemas, o faltaran fotografías.

\begin{tabular}{|c|c|}
\hline \multicolumn{2}{|r|}{ Taller de retrato y relato } \\
\hline Preguntas & Respuestas \\
\hline ¿Qué es la memoria? & $\begin{array}{l}\text { - Lo que pensamos o se nos ocurren las cosas. } \\
\text { - Recordar las cosas. } \\
\text { - Lo que has vivido. } \\
\text { - Es un recuerdo. }\end{array}$ \\
\hline ¿Qué recordamos? & $\begin{array}{l}\text { - Lo bonito que nos pasa. } \\
\text { - Lo que nos pasó ayer. } \\
\text { - Momentos tristes y los momentos felices como la primera } \\
\text { comunión, las bodas, la confirmación o cuando perdiste a alguien. } \\
\text { - Fechas importantes. } \\
\text { - Momentos de nuestra historia. } \\
\text { - Recuerdo de cada cosa especial que vivimos. } \\
\text { - Fechas tristes y fechas felices. } \\
\text { - Personas. }\end{array}$ \\
\hline $\begin{array}{l}\text { ¿Para qué } \\
\text { recordamos? }\end{array}$ & $\begin{array}{l}\text { - Por la emoción de recordarse de momentos o personas perdidas. } \\
\text { - Momentos vividos. } \\
\text { - Para conmemorar algo. } \\
\text { - Revivir momentos. }\end{array}$ \\
\hline ¿Cómo recordamos? & $\begin{array}{l}\text { - Pensando. } \\
\text { - Acordándose. } \\
\text { - Cicatrices. } \\
\text { - Fotos (cuando las ves). } \\
\text { - Las imágenes. } \\
\text { - Las fechas. } \\
\text { - La historia de voz en voz. }\end{array}$ \\
\hline $\begin{array}{l}\text { Y la memoria } \\
\text { histórica ¿a qué se } \\
\text { refiere? }\end{array}$ & - Lo que se vivió hace tiempo. \\
\hline $\begin{array}{l}\text { ¿Y si los muros de la } \\
\text { iglesia hablaran? }\end{array}$ & - Nos podrían contar toda su vida desde su creación. \\
\hline
\end{tabular}

Tabla 3. Taller Retrato y Relato. Actividad 1. 
Con la actividad se reflexionó sobre las maneras de recordar, y es una introducción a la documentación desde la fotografía como un medio idóneo para retratar la cotidianidad y los gremios patronales de Popolá con las jóvenes como participantes y autoras de la documentación, desde la identificación previa de los elementos que componen los gremios patronales. La siguiente actividad correspondió al trabajo de campo con las jóvenes, en el cual tuvieron que alistar las cámaras y salir a la calle a realizar las fotografías.
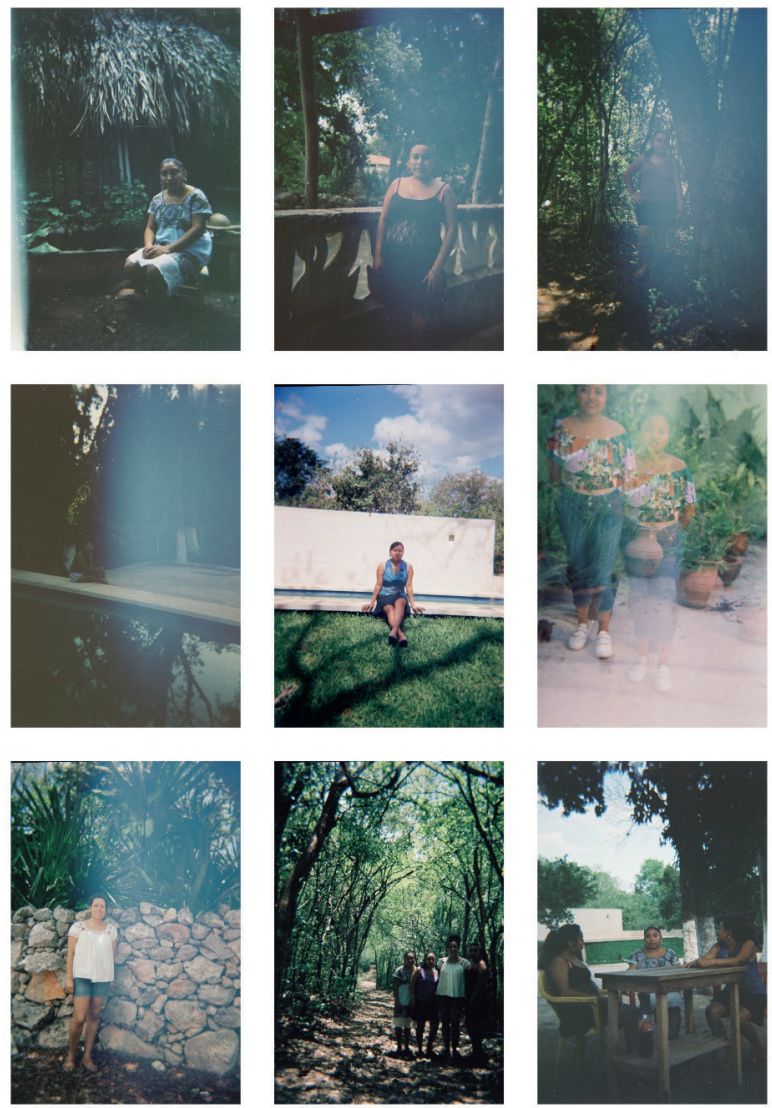

Ilustración 1. Retratos del grupo de investigación. De izquierda a derecha y arriba abajo: Elena, Cristina, Magda; Lucy, Deysi, Brenda; Natalia; todas en los caminos por las milpas y en casa de Cristina. Cámara Holga $120 \mathrm{~N}$, con $120 \mathrm{~mm}$ Film. 
Para familiarizarnos con las cámaras y el proceso de tomar las fotografías realizamos una pequeña clase del manejo y el mecanismo de las cámaras de plástico. Consistió en aprender a ajustar el foco según la distancia del objeto a retratar, tomar la foto y pasar el negativo a la siguiente foto. En este primer encuentro con la cámara análoga, en un recorrido por el pueblo y los terrenos de cultivos de los padres de Cristina y Magda, nos retratamos de manera individual en espacios que cada quien escogió. De esta manera, Natalia retrató a Elena; Elena, a Cristina; Cristina, a Natalia; a Magda la retrató su sobrina, que nos acompañaba, y Magda, posteriormente, retrató a Deysi, Lucy y Brenda, que aquel día no nos acompañaron en el recorrido.

En este acercamiento con la toma fotográfica se observaron entusiasmadas al no poder observar inmediatamente el resultado sino esperarlo hasta terminar el rollo y revelarlo en el laboratorio. Finalmente, las cuatro cámaras fotográficas las dejé con las jóvenes y en sus momentos libres o durante la participación en los gremios que transcurrían del 1 al 13 de mayo se acercarían a tomar las fotos.

El entusiasmo duró poco para ellas y, al contrario de lo que esperaba y pensaba, no tomaron fotografías en mi ausencia, asistieron únicamente a uno de los gremios (al que no llevaron sus cámaras), ya que me comentan que sus labores cotidianas no les permitían salir; ni siquiera el día del gremio mayor en casa de Elena vinieron. De esta manera, el sentido esperado de esta investigación en la cuestión de la fotografía por ellos mismas y observar los modos de retratarse no fue posible en su sentido completo; Lucy fue la única que asistió al gremio mayor y que tomó fotografías. Con este hecho, considero que se podrían tener mejores resultados con un grupo cerrado y constante, para que el resultado sea parte de una calificación, como, por ejemplo, con niños de una escuela o con jóvenes de la secundaria. 


\section{Taller de retrato y relato}

\section{Objetivo}

Capturar momentos, personas y elementos de los gremios a la Virgen de Fátima del 1 al 13 de mayo.

\section{ACTIVIDAD 2}

- $\quad$ Toma de fotografías de los elementos identificados del gremio:

¡Retratoy relato!
El gremio
Las velas
Los ramilletes
Los voladores
Los estandartes
El pan águila
La Virgen de Fátima
La comida del gremio
Las procesiones
Los cantos
Los novenarios
Las misas

- Revelado de fotos en un laboratorio de fotografía

- Relato de los retratos. Se dispusieron en una hoja las fotografías ampliadas en papel y se realizó un relato individual entre las jóvenes del retrato observado. De tal manera que se obtuvo información por varias manos del mismo relato.

Tabla 4. Taller de retrato y relato. Actividad 2.

No obstante, estuvieron atentas al resultado del revelado de las fotos, de nuestros retratos y de las fotos tomadas por Lucy y por mí, los negativos los llevé a un laboratorio en Mérida y nos reunimos una vez las teníamos impresas para realizar los relatos entre todas. Fue una sesión de dos días, una en Valladolid y otra en Popolá. Entre un guacamole y un agua de guayaba hicimos una sesión de escritura de relatos de las fotos impresas. Las pegamos con cinta en la parte superior de unas hojas de papel grandes para tener suficiente espacio para escribir todas. La siguiente sesión fue en casa de Cristina, donde habitualmente nos reuníamos, en esta ocasión 
asistieron todas menos Lucy, que se encontraba enferma, Deysi llegó con huayas y ciruelas (las frutas de temporada) de su terreno para compartir entre todas. A continuación, se encuentra uno de los resultados, la fotografía con los respectivos relatos por las jóvenes investigadoras.

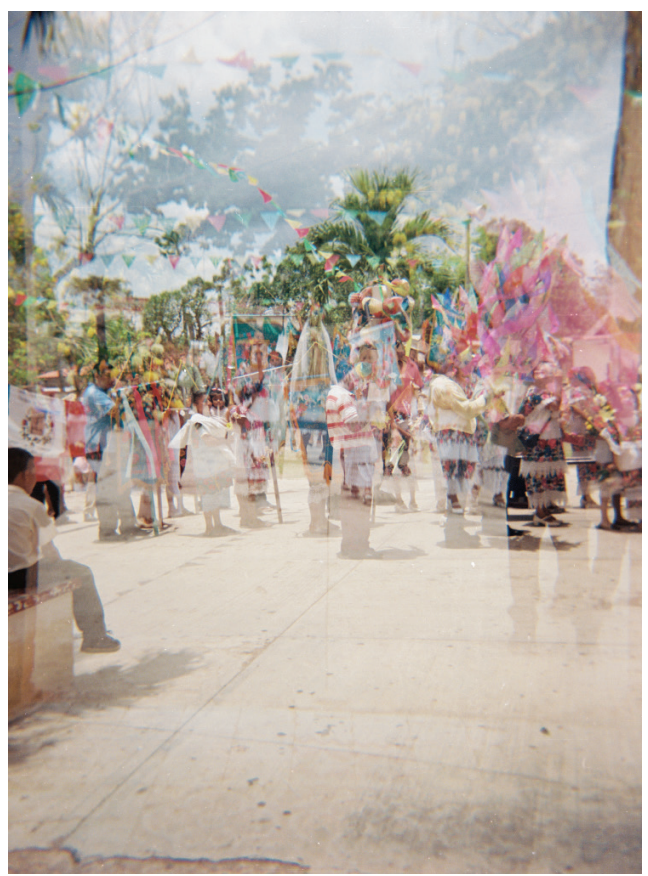

Ilustración 2. Procesión de la Virgen de Fátima de Popolá durante el gremio mayor. Foto: Lucy María Tut Pech. Ejercicio de doble exposición con la cámara Holga 120N.

Llegando con el gremio en la iglesia. Las jóvenes con sus ternos muy hermosos hacen la participación de llevar a la Virgen de Fátima y también sostener las flores, estandartes y velas y los señores son los que se encargan de sostener los ramilletes (Lucy, relato escrito).

La gente del pueblo están entrando en la iglesia con la virgen, los estandartes, el ramillete y muchas flores de la mano porque están contentos de ir en procesión con las gentes, tanto adultos como niños portan trajes típicos como el hipil o el terno porque es una gran fiesta celebrar el cumpleaños de la Virgen de Fátima (Elena, relato escrito). 
Es una bonita tradición de este hermoso pueblo, la imagen nos muestra cómo la gente llega después del recorrido que hacen, lo colorido de los hipiles y ternos son hermosos, ya cuando entren en la iglesia se hace una misa del devoto y en la tarde se hace una novena y amaneciendo es el gran día de Nuestra Señora de Fátima, una misa hermosa y muy organizada con los voladores, los ramilletes los estandartes son algo hermoso (Brenda, relato escrito).

Por su parte, la difusión de resultados se refiere a las maneras en las cuales se propuso disponer la información recolectada en la investigación conjunta con las jóvenes investigadoras, lo que corresponde a uno de los objetivos generales de la investigación, para su uso, disfrute y difusión no solo por su parte, sino para el resto de la población. Esta visualidad electrónica (Martín-Barbero y Corona Berkin, 2017) propuesta en nuestro marco conceptual y teórico se propuso alcanzar por medio de los recursos electrónicos que los jóvenes del pueblo de Popolá presentan.

Después de observar e identificar que la mayoría de jóvenes cuenta con perfiles de Facebook, se determinó esta plataforma como el medio idóneo para alcanzar esta nombrada visualidad electrónica. La mayoría de los jóvenes tienen smartphones y señal de celular con datos que posibilitan su acceso a la red, lo cual permitiría un mayor alcance de las publicaciones. La causa de que esta población tan numerosa -más de 5.000 habitantes-cuente con perfecta señal de telefonía celular corresponde a que se localiza a pocos kilómetros de Valladolid, el centro urbano más importante del oriente de la península de Yucatán, con un poco menos de 50-000 habitantes.

De esta manera, se creó una página de Facebook después de considerar la posibilidad de usar otras redes sociales como Wordpress, Tumblr o Instagram, que se descartaron debido a que su uso es más complicado y la población de jóvenes no conoce estas redes todavía y no hace uso de ellas. Así, si ya existe una red virtual en la comunidad a través de Facebook, se aprovecharía para nuestros intereses culturales de difusión de las costumbres del pueblo. 


\section{Conclusiones}

Es posible definir a los gremios de Popolá como una costumbre (Hobsbawm, 2002) que va más allá de una devoción y representa el momento de compartir y de reafirmar los lazos de compadrazgo; rendir culto a la Virgen a través de esta práctica une el sentido de identidad del grupo social. Las celebraciones patronales se realizan tres veces al año, en enero durante 24 días, en mayo durante 13 y en septiembre durante 23 días. Representan 60 días del año en donde en 60 familias efectúan ofrendas a los patronos del pueblo, es decir, el $48 \%$ de la población participa dentro de sus núcleos familiares, es la consolidación de lo socialmente compartido. Es un hecho que a escala familiar se gestan las relaciones de más confian$\mathrm{za}$, aquellas que unen bajo un mismo abrazo eso que los hace grupo. Lo socialmente compartido (Giménez, 2004) por los habitantes de Popolá es lo socialmente construido en el núcleo familiar y de compadrazgos que se extiende formando una red que abarca a casi la totalidad de la población.

El sujeto-investigador extranjero -yo como colombiana en un contexto mexicano, yucateco y maya - fungió como el origen de un diálogo intercultural, ya que mi presencia remarca su diferencia y sus particularidades. Los cuestionamientos que realizan sobre las maneras en cómo se celebra o rinde honor a los santos patronos de mi pueblo, o si se come tortilla o no, o «iqué se come por allá?», son algunos ejemplos de ello. También, partí de una posición privilegiada en el sentido de que era una cara conocida y les extrañaba verme de regreso sin ningún objeto que restaurar de por medio, no obstante, la idea de la documentación de los gremios como método de preservación fue concisa, ya que reconocen que existen cambios en las celebraciones o presienten que existirán.

El grupo de investigación creado con las jóvenes y los encuentros semanales que mantuvimos conformaron el espacio generado para la reflexión y el diálogo intercultural. El taller de retrato y relato fue el paso metodológico que se consideró que daba las herramientas a las jóvenes para tomar parte acción en la investigación, que las motivaría como elemento de reflexión de la «acción del retrato de un tiempo» que inevitablemente se transformará. Pensé que el interés surgiría espontáneamente conforme avanzábamos e identificábamos, clasificábamos y categorizá- 
bamos las prácticas sociales, y que con el inicio de los gremios se intensificaría al salir al campo a explorar y observar los elementos clasificados y las personas clave del gremio; no obstante, no fue así. Posiblemente, de continuar ellas como maestras de catequesis — como las conocí hace tres años-y lo investigado fuera posible llevarlo a sus clases con los niños del pueblo, podría haber existido un interés exponencialmente más alto. La falla consistió en la falta de sesiones más continuas y que «obligaran» a los jóvenes a cumplir deberes. Falto interés por su parte y no dejaron de ver nuestros encuentros como una ayuda a mi tarea de tesis y no como un proyecto del cual apropiarse.

De esta manera, el trabajo etnográfico fue adoptando otra forma no esperada; uno de los momentos en que el esquema metodológico fue flexible para cambiar de perspectiva fue al conocer que la familia de Elena era la encargada del gremio mayor, momento en el que decidí concentrar los esfuerzos en la documentación esos días. Esto, con la idea de que las jóvenes participaran en los gremios del 1 al 13 de mayo, pero sobre todo en el gremio mayor en casa de su amiga Elena para allí documentar entre todas, con el incentivo de que tomaran la herramienta de trabajo prevista - la cámara - y salieran a los gremios y otras prácticas que acontecían en Popolá los días de los gremios sin necesidad de que yo estuviera con ellas. Esta perspectiva de acción se basa en la idea tratada de Appadurai (2015) del investigador innato que todos tenemos y que sin necesidad de convertirlo en un deber, por ser parte de tu tarea, saldría naturalmente en las jóvenes. Lucy fue quien logró despertar el ser investigativo que todos tenemos y se animó a salir a tomar fotos el día del gremio mayor. Sus fotos, junto con las mías, ilustran esta etnografía.

No se logró el cometido de que el retrato fotográfico se convirtiera en el medio de documentación de su cotidianidad, por timidez a la hora de tomar fotos frente a su comunidad o sencillamente por no asistir a los gremios. No obstante, en los relatos orales y escritos la participación fue activa, en ellos contaron y redactaron su perspectiva de los gremios, en los que se conoció el sentido simbólico del gremio en cada actividad.

En definitiva, la experiencia de la etnografía colaborativa como método de investigación ha resultado fructífera en el sentido de los aciertos 
y los errores que se obtuvieron en su metodología; sin embargo, no se cumplió dar voz cabalmente a los sujetos-investigados desde la imagen, aunque sí desde el relato. El diseño de un proceso metodológico más meticuloso y estricto y explorar la posibilidad de trabajar con otro grupo de jóvenes de las escuelas o colectivos ya conformados con los que se adquiera un compromiso mayor por los resultados previstos son aspectos a evaluar, ya que esta falta dificultó tener una continuidad en la investigación con el grupo de jóvenes. Por ello no existieron en cada paso metodológico un acompañamiento, discusión y análisis colectivo. Estas son solo unas de las críticas y mejoras posibles al diseño de la investigación presentada en este escrito.

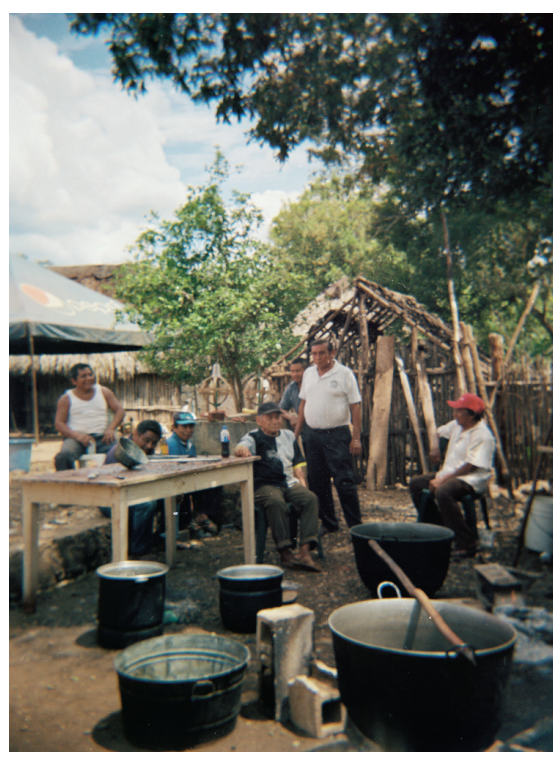

Ilustración 3. Proceso de cocción de la morcilla y la chicharra. Foto: Natalia H. Tangarife. Fotografía de formato mediano tomada con una cámara Holga 120N.

En un evento se necesita mucho la participación de los señores, por eso hay que invitar a varios, pues en este caso del gremio llegan en la tarde de 1o de mayo para empezar con su labor, van a buscar a los cochinos, pasan a prestar banquillos, mesas, banquetas, pailas, empiezan a armar toldos y hacer las fogatas para el nixtamal y empiezan a cavar el pib [hueco para la cocción de la comida], y para el 11 de mayo llegan como a las 3:00 de 
la mañana para matar al cochino y lavan el nixtamal algunos, otros, los que sí saben, pues ponen los calderos en el fuego para empezar a hacer las chicharras y lo van moviendo con un palo y los otros van empezando a llevar el pib con piedras, leñas y troncos de la mata de plátanos. Y para terminar entierran el pib y para el 13 de mayo pues solo desentierran el pib y llevan los botes de nixtamal al molino porque pesan y luego pues busca cada quien en qué ayudar (Elena, relato escrito).

La mayoría de las personas como se acostumbra hacen la morcia, se rellena con carne, chile, anjus para darle sabor, es una comida muy rica y me encanta comerla (Magda, relato escrito).

Retomando otro aspecto de la investigación referente a su propósito como medio de documentación de las herencias culturales, los relatos realizados por las jóvenes corresponden al aspecto que se logró construir colectivamente en esta investigación. Con ellos y las fotografías análogas y digitales realizadas durante los gremios y las diversas actividades preparativas, se propuso realizar la difusión de los resultados para disfrute de los habitantes en general. La visualidad electrónica (Martín-Barbero y Corona Berkin, 2017) que induce los referentes materiales y simbólicos de otras culturas a nuestros conocimientos, esa transferencia en una sola dirección, puede usarse en sentido inverso para extender de aquí hacia allá lo que nos pertenece.

Facebook podrá cumplir con su cometido. La extensión del uso del celular inteligente sobre la población joven, como la edad de nuestras jóvenes, nos lleva a que el contenido de la página de @retratosdepopola tenga 400 likes o seguidores directos. Esta página se creó no únicamente para efectos de publicar esta investigación, sino para continuar usándola como plataforma y publicar otras investigaciones sobre las costumbres de Popolá o al realizar nuevas actividades al continuar visitando Popolá para terminar de restaurar otras imágenes de la iglesia. De esta manera, la circulación de significados (Grimson, 2009) que buscamos también empieza a tener visualización bidireccionalmente. El manejo de la página por Lucy y Magda continúa siendo bajo, pero tenemos todavía mucho material por publicar, por lo que seguiré insistiendo en que lo hagan. 
Finalmente, aunque el planteamiento teórico fue utópico en su apartado del cambio social referente al devenir de las herencias culturales por parte de los jóvenes al investigar el contexto inmediato al que pertenecen, es una experiencia que lleva a la reflexión, cumple el cometido como primera experiencia en campo y la construcción de una investigación colaborativa que sale de la observación participante para ejercer algo de intervención social. Tal como Blanca Muratorio (2005) nos recuerda, el trabajo de campo del antropólogo es una presencia compartida con la cual «tratamos de comprender cómo los otros seres humanos resuelven las situaciones cotidianas que confrontan» (Muratorio, 2005: 131).

A partir de esta experiencia, reconozco que la intervención a través de la etnografía colaborativa requiere de un diagnóstico más acusado que evidencie una problemática sobre la cual fijar la intervención. En este caso, tomar a los gremios patronales de Popolá como objeto de estudio se sustenta bajo la premisa de que estos, y muchas otras costumbres del conjunto del pueblo maya-hablante, se perciben como elementos susceptibles de rápidas transformaciones por el proceso de aculturación que acontece. Así, la necesidad de su preservación como patrimonio vivo de un espacio-tiempo a través de la documentación se ve determinante para aquellos que nos dedicamos a la salvaguarda del patrimonio cultural.

Por aquella razón, hacer este proceso de preservación en un espacio dialógico de reflexión y de aprendizaje con los maya-hablantes de Yucatán es necesario para ingresar en aquella circulación de significados desde el reconocimiento de lo propio, obtener las herramientas para ingresar en ella y generar bidireccionalidad en el proceso. Esto es algo que se espera alcanzar a través del uso de las redes sociales, dar visibilidad al pueblo maya en otras latitudes desde sus propias publicaciones, por ello los relatos de los retratos cumplen esta función.

Los retratos fotográficos resultantes de esta investigación enseñan una visión diferente del actor-sujeto investigado. El retrato artístico alcanzado por el uso de una cámara análoga que permitió y generó un espacio de experimentación nos revela una postal diferente que sobresale de un retrato simple en primer plano. Nuestras fotos demuestran el proceso, se siente desde la doble exposición la práctica social en acción, no 
estática, sino en movimiento. El sujeto permanece como sujeto, la foto es objeto del instante en movimiento, de la experiencia de realidad compartida.

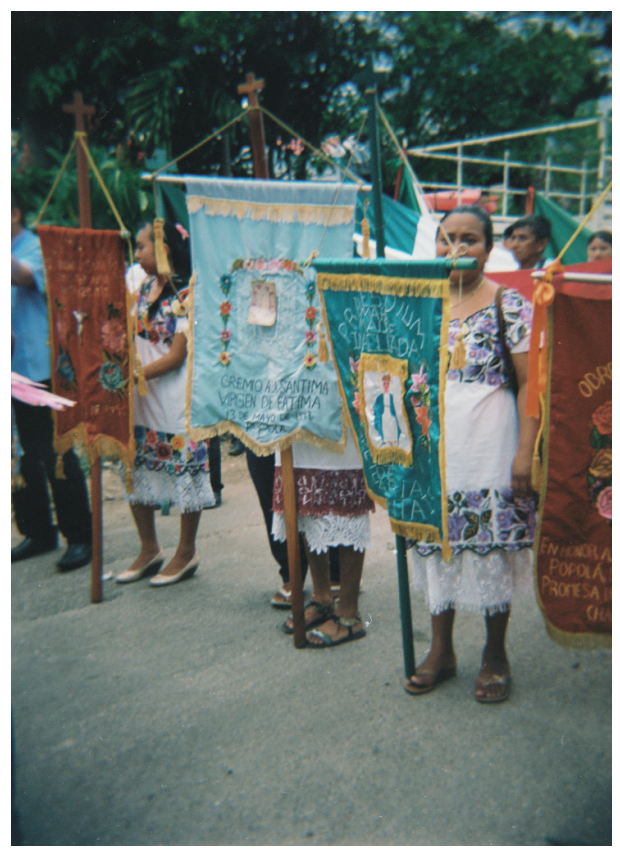

Ilustración 4. Estandartes durante la procesión del gremio del 12 de mayo. Foto: Lucy María Tut Pech.Fotografía de formato mediano tomada con una cámara Holga 120N.

Los estandartes son muy hermosos y lo que hace la gente es donarlos en la iglesia y como persona devotante cada quien lo puede hacer o decorar como uno quiera. Estos estandartes tienen fechas y año en que fueron donados (Lucy, relato escrito).

En esta foto vemos a las personas que tienen agarrados los estandartes y los estandartes no son comprados, más bien son donados por personas de fe, o a veces por alguna enfermedad hacen su limosna de regalar a la virgen de Fátima (Magda, relato escrito).

Los estandartes son un símbolo muy importante en el gremio, las procesiones y las misas, ya que realzan mucho la vista en el recorrido de donde sale el gremio y la iglesia, algunos estandartes son de centros pastorales y algunos son especiales para quien agarra el gremio, le dan su 
estandarte y lo utilizan para llevarlo cuando lo inviten a otro gremio, tienen un saludo especial, cuando son estandartes de otro lugar se juntan las crucesitas entre cada estandarte y es su saludo (Elena, relato escrito).

\section{Bibliografía}

Appadurai, A. (2015). «La investigación como derecho humano». En El Futuro como Hecho Cultural (pp. 355-374). Buenos aires: Fondo de Cultura Económica Argentina.

Assmann, H. y Boff, L. (2002). Placery ternura en la educación: hacia una sociedad aprendiente. Madrid: Narcea.

BARTHES, R. (1989). La cámara lúcida: nota sobre la fotografia. Barcelona [etc.]: Paidós.

Bartolomé, M. A. (1997). Gente de costumbre y gente de razón: las identidades étnicas en México. México, D.F.: Siglo Veintiuno Editores. Recuperado de: $<$ http://cataleg.urv.cat/record=b1156144 S13*cat $>$.

Bartolomé, M. A. (2006). «Los laberintos de la identidad. Procesos identitarios en las poblaciones indígenas». Ava, (9), 28-48.

BRACAMONTE y SOSA, P. (1994). «El cristianismo de los mayas yucatecos». Recuperado de: <http://www.mayas.uady.mx/historia/hp_02.html >.

Bracamonte y Sosa, P. y Lizama Quijano, J. (2003). «Marginalidad indígena: una perspectiva histórica de Yucatán». Desacatos, 13, 83-98.

BuRke, P. (2001). Visto y no visto: el uso de la imagen como documento histórico. Barcelona: Crítica.

Dietz, G. (2012). «Reflexividad y diálogo en etnografía colaborativa: el acompañamiento etnográfico de una institución educativa «intercultural» mexicana». Revista de Antropología Social, 21, 63-91.

Eco, U. (1976). Signo. Barcelona: Labor.

FARRISS, N. M. (2012). La sociedad maya bajo el dominio colonial: la empresa colectiva de la supervivencia. México, D.F.: Artes de México, INAH \& CONACULTA.

FREIRE, P. (1976). La Educación como práctica de la libertad. México, D.F. [etc.]:Siglo XXI. Recuperado de: <http://cataleg.urv.cat/record=b1024754 S13*" cat>. 
García Canclini, N. (2014). «Diferentes, desiguales o desconectados». Revista CIDOB d'Afers Internacionals. Representaciones e Interculturalidad, 66-67, 113-133.

Giménez, G. (2004). Culturas e Identidades. Revista Mexicana de Sociología, UNAM, 66 Especia(oct.), 77-99.

Grimson, A. (2009). «Las culturas son más híbridas que las identificaciones». Diálogos Inter-Antropológicos. Anuario Antropológico 2007-2008, 223-267.

HobsBawm, E. J. (2002). «Introducción. La invención de la tradición». En E. J. Hobsbawm y T. Ranger (eds.). La Invención de la Tradición. Barcelona: Crítica.

Kingman Garcés, E. (2011). «¿Podemos pensar el patrimonio? Políticas de la memoria, el patrimonio y la seguridad». Arxiu d'Etnografia de Catalunya, (11). Recuperado de: <http://antropologia.urv.cat/revistarxiu>.

Magazine, R. (2012). «El otro como sujeto, la modernidad como conducto: la producción de subjetividades en un pueblo mesoamericano». En Iberoamérica-Vervuert (ed.). Modernidades Indígenas. Madrid.

Martín-Barbero, J. y Corona Berkin, S. (2017). Ver con los otros. Comunicación intercultural México, D.F.

Muratorio, B. (2005). «Historia de vida de una mujer amazónica: intersección de autobiografia, etnografía e historia». ICONOS, 21, 129-143.

Panikkar, R. (2006). Decálogo: cultura e interculturalidad. Cuadernos Interculturales. Universidad de Plata Ancha. Viña Del Mar. Chile, 4(6, primer semestre), 129-130.

PéRez Ruiz, M. L. (2015). Ser joven y ser maya en un mundo globalizado. México, D.F.: Instituto Nacional de Antropología e Historia.

Pérez Ruiz, M. L. y Argueta Villamar, A. (2011). «Saberes indígenas y diálogo intercultural». Cultura y Representaciones Sociales, 5(10).

Pitarch, P. (2012). «La ciudad de los espíritus europeos. Notas sobre la modernidad de los mundos virtuales indígenas.» En IBEROAMERICA-Vervuert (ed.). Modernidades Indígenas. Madrid.

Pujadas, J. J. (2006). «Hybrid Identities in Contexts of Minorisation of Citizens: Thinking about the Indigenous Peoples of Latin America» (pp. 183-211). 
Pujadas, J. J. (2011). «Los claroscuros de la etnicidad. El culturalismo evaluado desde la óptica de la cohesión social y la ciudadanía». En A. Palenzuela (comp.) y P Olivi (ed.). Etnicidad y desarrollo en los Andes (pp. 25-51). Sevilla: Universidad de Sevilla .

RAPpaport, J. y RAmos PACHO, A. (2005). «Una historia colaborativa: retos para el diálogo indígena-académico». Historia Crítica, 29.

RODRíguez BECERRA, S. (2012). «Nuevas perspectivas sobre la religiosidad popular o religión común de los andaluces». Gaceta de Antropología, 28(3).

Todorov, T. (2013). Nosotros y los otros: reflexión sobre la diversidad humana. España: Siglo Veintiuno.

WANG, C. (1999). «Photovoice: A participatory action research strategy applied to women's health». Journal of Women's Health, 8(2), 185-192. 